\title{
Experimental Study on the Mechanical Behavior of High Water Content Dredged Materials Stabilized by Cement and Super-absorb Polymer
}

\author{
Xia Bian ${ }^{1,}$, , Zhifeng Wang, b \\ ${ }^{1}$ Geotechnical Research Institute, College of Civil and Transportation Engineering, Hohai University, \\ Nanjing Jiangsu 210098, P. R. China \\ 2 Department of Geotechnical and Tunnelling Engineering, School of Highway, Chang'an University, \\ Xi'an, Shanxi 710064, P. R. China \\ axia.bian@hhu.edu.cn, b zhifeng.wang@chd.edu.cn
}

Keywords: dredged material; cement stabilized clay; super-absorbent polymer; high water content. Abstract. A series of unconfined compression strength test and odeometer test were conducted to study the mechanical behavior of cement stabilized dredged material at high water content with super-absorb polymer. The super-absorbent polymer (SAP) is added as water reducing agent into the cementing agent to improve the effectiveness of cementation for high water content dredged material. Test results show that the unconfined compressive strength $\left(\mathrm{q}_{\mathrm{u}}\right)$ increases with increasing SAP content, the strength increase is about 2.4 times when SAP content is of $10 \%$. For certain cement content, the compression curve of cement stabilized clay with higher SAP content lies blow that of lower ones, as a result, the vertical yield stress $\left(\sigma_{\mathrm{vy}}^{\prime}\right)$ increase with the SAP content.

\section{Introduction}

Large volumes of sediment are dredged annually to maintain the navigational depth of channels and harbors and to prevent rivers from flooding ${ }^{[1-5]}$. Xu (2013) ${ }^{[6]}$ reported that more than 14 billion $\mathrm{m}^{3}$ per year soil martials are dredged from main rivers and commercial ports in China by 2015. Most of the dredged material is simply dumped in the sea or stored on land disposal sites ${ }^{[7-8]}$. Hence, to make the abandoned material useful for engineering construction, the stabilization-solidification method via cementing agents is often introduced to improve the mechanical behavior of dredged material. It should be emphasized that previous studies are mainly focused on the water content of cement solidified clays less than 2 times of their liquid limit. However, the typical water content of dredged clay in storage yard in China is about 3 times of liquid limits ${ }^{[5-6]}$. Due to the high amount of initial water content, the strength development of cemented dredge material is lower than that of typical soft clay, resulting in a reduction in cementation efficiency. Therefore, to improve the strength characteristics of dredged clay with high water content, large amounts of cement material or additional additives are expected to be consumed.

At present, a type of high molecular polymer which possess strong water absorbing capacity, termed as super-absorbent polymer (SAP), is often used as a water reservoir to improve the self-desiccation of concrete ${ }^{[9-10]}$. To explore the use of SAP, Bian ${ }^{[11]}$ introduced SAP as a water reducing agent into cement mixing method to improve the strength properties of cement stabilized soil with notably high water content.

The present paper investigates the influence of SAP content on unconfined compressive strength (UCS) and compressibility of solidified dredged material at high water content.

\section{Materials and Experimental Procedure}

Tested soil. The clay used in this study was taken from the land reclaimed by the deposition of soils dredged from Qinghuai river, Nanjing city China. The basic physical properties of the untreated Nanjing clay are summarized in Table 1. According to the Unified Soil Classification System ${ }^{[12]}$, the Nanjing clay can be classified as high plasticity clay $(\mathrm{CH})$. The in-situ water content of Nanjing clay is $50 \%$. 
Table 1. Basic physical properties of Nanjing clay

\begin{tabular}{lllll}
\hline \hline Soils & $\mathrm{G}_{\mathrm{s}}: \mathrm{Mg} / \mathrm{m}^{3}$ & Liquid limit: \% & Plastic limit: \% & $\begin{array}{l}\text { Activit } \\
\mathrm{y}\end{array}$ \\
\hline Nanjing Clay & 2.67 & 52.0 & 23.0 & 1.20 \\
\hline \hline
\end{tabular}

Type I ordinary Portland cement were used in this study as the cement binder. The SAP used in this study was made of a suspension-polymerized, covalently cross-linked acrylamide/acrylic acid copolymer with a dry-bulk density of $800 \mathrm{~kg} / \mathrm{m} 3$. The diameters of spherical particles varied from $120 \mu \mathrm{m}$ to $150 \mu \mathrm{m}$ in dry state. The SAP particle has a water absorption capacity of $20 \mathrm{~g}$ water per gram of SAPs.

Specimen Preparation and Testing. To prepare stabilized soil samples, the samples were completely remolded and then the de-aired distilled water was added to achieve a slurry with water content at $156 \%$ (3 times liquid limits) to simulate the typical water content of dredged material in disposal pond in China. A predetermined quantity of additives (cement and SAP) was then poured into the initial slurry and the binary mixture was agitated thoroughly for 5 min to achieve uniformity. Two cement content of 5\% and 10\% (dry soil weight basis) was adopted and three levels of SAP content $(1 \%, 5 \%$ and $10 \%$, dry soil weight basis) were selected.

The homogeneous paste was then transferred into oedometer rings (diameter $61.8 \mathrm{~mm}$, height 20 $\mathrm{mm}$ ) as well as to cylindrical containers of $50 \mathrm{~mm}$ diameter by $100 \mathrm{~mm}$ height, taking care to eliminate any air entrapment during this procedure. After 24 hours the cylindrical samples were dismantled. All the cylindrical samples and the same as along with oedometer rings were then wrapped in plastic bags and cured in a controlled environment $\left(20{ }^{\circ} \mathrm{C}\right.$ and $95 \%$ relative humidity) until the lapse of different curing times. After curing, the samples were soaked under water and were then subjected to vacuum for $8 \mathrm{~h}$ to facilitate saturation prior to the oedometer tests and unconfined compression test. Oedometer tests were carried out after 28 days of curing. Unconfined compression tests were run on samples after 7, 14, 28 and 90 days of curing. The rate of vertical displacement in unconfined compression tests was $1 \mathrm{~mm} / \mathrm{min}$.

\section{Results and Discussions}

Unconfined Compressive Strength Results. The typical stress - strain curves are shown in Fig. 1. The sample ID $(3 \mathrm{~W}+5 \mathrm{C}+1 \mathrm{~S})$ in Fig. 1 represents that the sample is remolded at 3 times the liquid limit, treated by $5 \%$ of cement content and $1 \%$ of SAP content. It can be seen from Fig. 1 that the failure strain ranges from $0.7 \%$ to $2.0 \%$, and it decreases with an increase in the curing time and SAP content. Whereas, the unconfined compression strength shows an increase tendency with curing time and SAP content. This indicates that the cement stabilized soil with higher strength show more brittle behavior during shearing. Similar findings have been reported by other researchers ${ }^{[13-14]}$.

Effect of SAP content on unconfined compression strength $\left(\mathrm{q}_{\mathrm{u}}\right)$ is shown in Fig. 2. Where, $\mathrm{q}_{\mathrm{u}, 0 \mathrm{O}}$ represents the unconfined compression strength of cement stabilized soil without SAP. Fig. 2 shows that SAP has significant effect on the strength increase for cement stabilized soil. By adding only $10 \%$ of SAP content, the increase in $\mathrm{q}_{\mathrm{u}}$ is up to about 2.4 times that without SAP in all the curing times. This behavior confirms that the SAP can be used as a sufficient additive to improve the strength behavior in the cement mixing method. Moreover, it appears that the strength increase for SAP content of $1 \%$ is about 0.5 to 1.3 times. Hence, if the budget of the project is limited, by adding relative small amount of SAP can improve the strength of cement stabilized soil especially at high water content significantly. In addition, it seems that the strength increase for different cement content are quite consistent at the same SAP content. This behavior suggests that the effect of SAP on the strength increase is not depend on the cement content. 


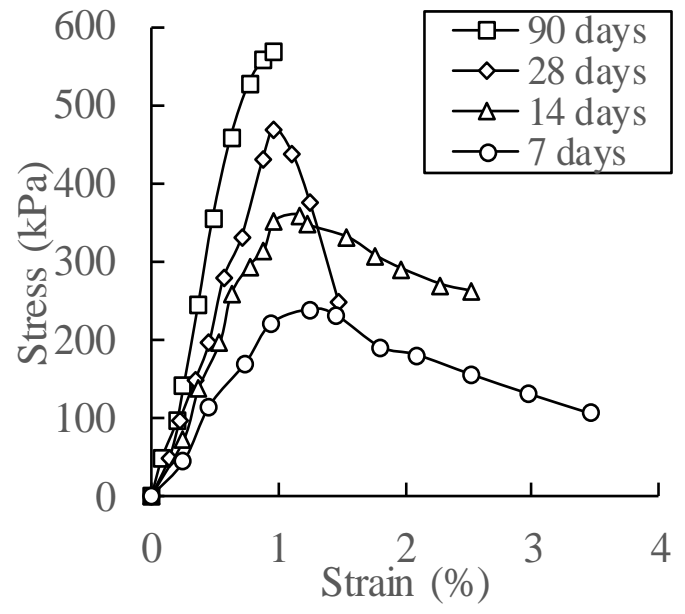

(a)

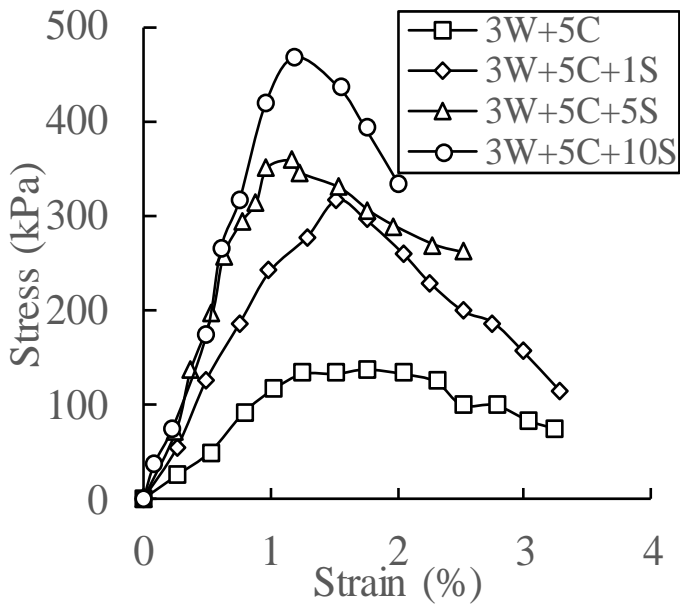

(b)

Fig. 1. Typical stress - strain curves (a) effect of curing time ( $3 \mathrm{~W}+5 \mathrm{C}+10 \mathrm{~S})$; (b) effect of SAP content (curing = 28 days)

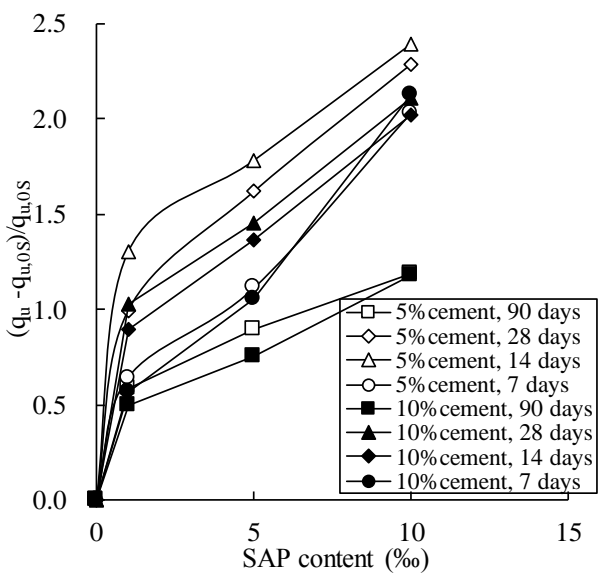

Fig. 2. Effect of SAP content on $\mathrm{q}_{\mathrm{u}}$

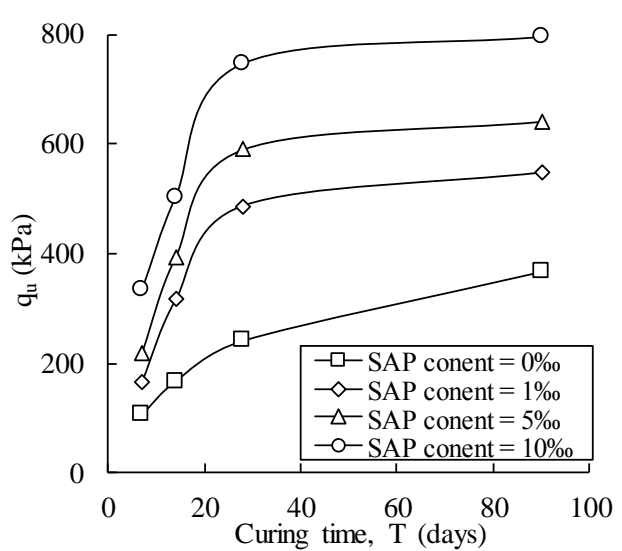

Fig. 3. Relationship between strength and curing time (cement content $=10 \%)$

The relationship between strength and curing time is presented in Fig. 3. The strength of cement stabilized soil increases with an increase in curing time. qu increases sharply with increasing curing time, when curing time increases from 7 to 28 days (approximately 2.4 times). Beyond this range, the increase in $\mathrm{q}_{\mathrm{u}}$ is less significant (the strength of 90 is about 1.3 times the strength of 28 days). It has been well documented that the strength increase with curing time is caused by the pozzolanic reaction that continues beyond 28 days ${ }^{[13-14]}$. More importantly, Fig. 3 shows that qu of the specimen with SAP is higher than that without SAP up to 90 days. Hence, it can be conducted that the role of SAP in strength increase continue throughout the whole process of pozzolanic reaction.

Oedometer Test Results. The typical one-dimensional compression curves obtained from oedometer tests are summarized in Fig. 4. It can be seen from Fig. 4 that for certain SAP content, the compression curve of the specimen with higher cement content lies below that of lower ones. More importantly, for certain cement content, the compression curve of the specimen with higher SAP content lies below that of lower ones. This behavior mainly attributes to the fact that SAP absorbs additional water in the specimen, which is equivalent to reducing the water content in cement stabilized soil. Hence, the higher is the SAP content, the lower is the apparent initial water content of the specimen. Consequently, the compression curve of cement stabilized soil with higher water content lies above that of lower water content ${ }^{[15-16]}$. Hence for certain initial water content and certain cement content, the reason why the compression line with increased SAP content at lower position could be attributed to the increased amount of water reduction due to the increase of SAP content ${ }^{[11]}$. 


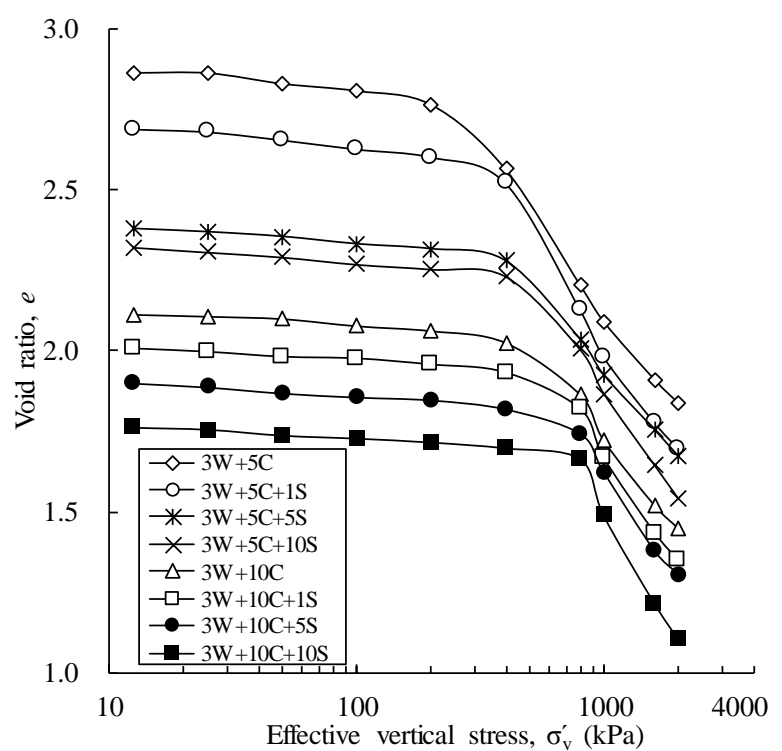

Fig. 4. Typical one-dimensional compression curves

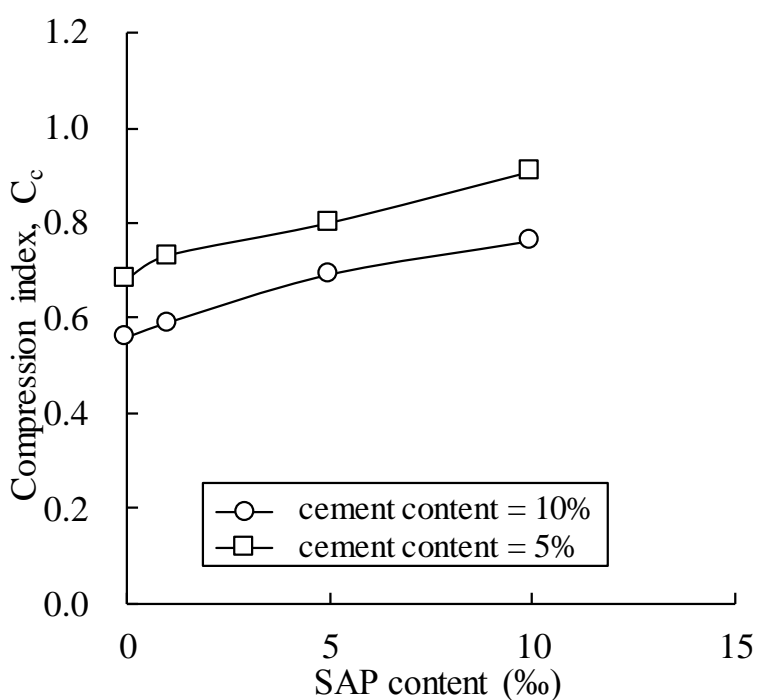

Fig. 5. Relationship between compression index and SAP content

Fig. 5 shows the variations of compression index $\left(\mathrm{C}_{c}\right)$ with SAP content. For certain SAP content, $\mathrm{C}_{c}$ significantly increases with cement content. The increasing compression index with cement content is due to the breakup of the stronger cementation bond formulating by pozzonlanic products from cement hydration process ${ }^{[15]}$. Meanwhile, $\mathrm{C}_{\mathrm{c}}$ slightly increase with SAP content. This behavior is mainly due to the fact that the effect of fabric plays a dominant role on the compressibility at post-yield state, which is determined by the amount of pozzonlanic products from cement hydration process. For certain cement content, the amount of pozzonlanic products is almost the same, and is independent of the SAP content. Hence, the compression index is primarily depended on the cement content rather than SAP content.

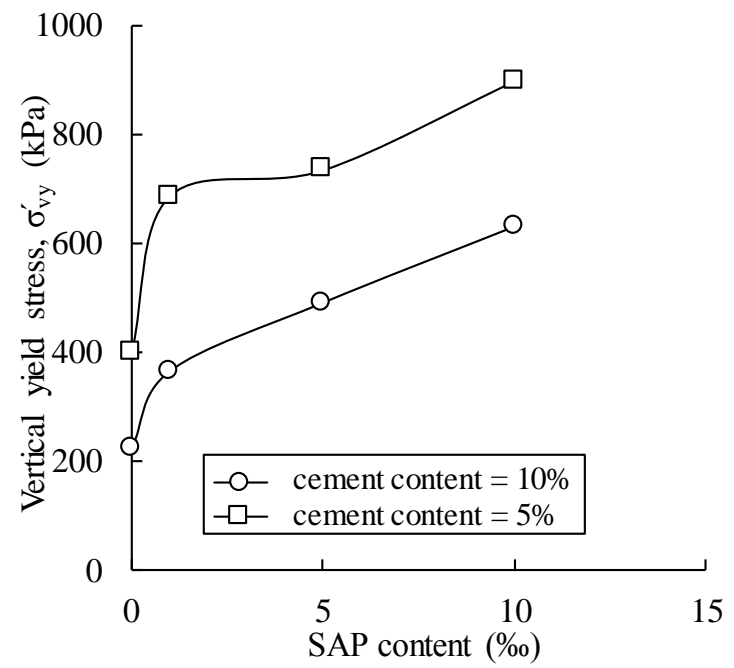

Fig. 6. Relationship between vertical yield stress and SAP content

The relationship between vertical yield stress $\left(\sigma_{\mathrm{vy}}^{\prime}\right)$ and SAP content is shown in Fig. 6. For certain SAP content, $\sigma_{\mathrm{v} y}^{\prime}$ increase with the increase of cement content which is consistent with previous researches. Fig. 6 also shows the effect of SAP content on the vertical yield stress. $\sigma_{\mathrm{vy}}^{\prime}$ increase is significantly when the SAP content increase from 0 to $1 \%$, and relatively small for higher SAP content. This behavior is consistent with the variation of strength.

In summary, it can be conducted that the effect of SAP on mechanical behavior of cement stabilized soil is not only to increase the unconfined strength but also to enhance the compressibility resistance. 


\section{Summary}

The main conclusions are summarized as follows:

1) For certain cement content, $q_{u}$ increases with increasing SAP content. The increase in $q_{u}$ is up to 2.4 times that without SAP for SAP content of $10 \%$. Hence, SAP is a sufficient additive to improve the strength of cement stabilized soil at high water content.

2) The compression line of cement stabilized clay with higher SAP content lies below that with lower ones at certain cement content. The vertical yield stress $\left(\sigma_{\mathrm{vy}}^{\prime}\right)$ increases with the increase of SAP content. Whereas the compression index $\left(\mathrm{C}_{\mathrm{c}}\right)$ is primarily depended on the cementing agent content rather than SAP content.

\section{Acknowledgements}

This study is supported by the National Natural Science Foundation of China (Grant No. 41502263) and the Natural Science Foundation of Jiangsu Province (Grant No. BK2015040806). In addition, a grant from the Fundamental Research Funds for the Central Universities of China in support of this study is also gratefully acknowledged.

\section{References}

[1] Tang, Y. X., Miyazaki, Y., and Tsuchida, T. Soils Found., 2001, 41(5), pp. 129-143.

[2] Zhu, W., Zhang, C. L., and Chiu, A. C. J. Geotech. Geoenviron. Eng., 2007, 133(5), pp. 588-598.

[3] Chiu, C. I., Zhu, W., and Zhang, C. L. Eng. Geol., 2008, 103(1), pp. 1-12.

[4] Kim, Y. T., Ahn, J., Han, W. J., and Gabr, M. A. J. Mater. Civ. Eng., 2009, 22(5), pp. 539-544.

[5] Xu, G. Z., Gao, Y. F., Hong, Z. S. Mar. Georesour. Geotec. 2012, 30(2), pp. 143-156.

[6] Xu, G.Z. Doctoral thesis, Hohai University, Nanjing, China, 2013.

[7] Satoh,T.,Tsuchida,T.,Mrrsukuri,K. and Hong,Z. Soils Found., 2001, 41 (5), pp. 145-154.

[8] Rekik, B., and Boutouil, M. Geo-Marine Lett., 2009, 29(3), pp. 171-179.

[9] Jensen, O.M., Hansen, P.F. Cem. Concr. Res. 2002, 32 (6), pp. 973-978.

[10] Justs, J., Wyrzykowski, M., Bajare, D., Lura, P. Cem. Concr. Res. 2015, 76, pp. 82-90.

[11]Bian, X., Wang, Z.F., Ding, G.Q., Cao, Y.P. Eng. Geol., 2016, 208, pp. 198-205.

[12] ASTM D2487. West Conshohocken, PA, 2011.

[13] Miura, N., Horpibulsuk, S., and Nagaraj, T. S. Soils Found. 2001, 41(5), pp. 33-45.

[14] Kamruzzaman, A. H. M., Chew, S. H., and Lee, F. H. J. Geotech. Geoenviron. Eng., 2009, 135(4), pp. 573-589.

[15]Lorenzo G. A., Bergado, D. T. J. Geotech. Geoenviron. Eng. 2004, 130 (10), pp. 1042-1050.

[16] Horpibulsuk, S., Miura, N., and Bergado, D. T. J. Geotech. Geoenviron. Eng., 2004, 130(10), pp. 1096-1105. 